\title{
PESQUISA DE Escherichia coli, Salmonella sp. E Staphylococcus aureus EM MAIONESES CASEIRAS COMERCIALIZADAS NO MUNICÍPIO DE JUAZEIRO DO NORTE-CE
}

\author{
RESEARCH OF Escherichia coli, Salmonella sp. and Staphylococcus aureus IN HOMEMADE \\ MAYONNAIS COMMERCIALIZED IN THE CITY OF JUAZEIRO DO NORTE-CE
}

Fernanda Déllis Lopes Laranjeiraa, Maria de Fátima Guedes Monteiroa, Cícero Roberto Nascimento Saraiva , Pedro Everson Alexandre de Aquino ${ }^{b}$, Mayara Macedo Limac, Dárcio Luiz de Sousa Júnior*, Maria Karollyna do Nascimento Silva Leandroa, Rakel Olinda Macedo da Silva , Lívia Maria Garcia Leandroa

\author{
Centro Universitário Dr. Leão Sampaio \\ Universidade Federal do Cearáb \\ Universidade Regional do Cariric \\ E-mail: darciolsjr@gmail.com
}

\begin{abstract}
RESUMO
O presente trabalho teve como objetivo avaliar as condições higiênicas e conservatórias de maioneses caseiras comercializadas no município de Juazeiro do Norte-CE. Através de análises microbiológicas, as amostras adquiridas foram inoculadas no meio de enriquecimento Brain Heart Infusion (BHI), onde permaneceram por 24 horas na estufa, em seguida as amostras inoculadas foram semeadas nos meios de cultura Agar Manitol Salgado, Ágar SS (Salmonella-Shiguella) e Agar Methylene Blue Eosin (EMB), após 24 horas foram feitas as identificações bacterianas através do método de coloração de Gram e provas bioquímicas para identificação das espécies. Foram coletadas 36 amostras, 80,6\% dessas apresentaram contaminação bacteriana, dentre as bactérias encontradas $89,6 \%$ foram Stapylococcus aureus, 6,9\% foram Escherichia coli e 3,5\% foram Salmonella sp. Os resultados obtidos por meio dessa pesquisa podem estar relacionados com o armazenamento e contaminação por higienização inadequada.
\end{abstract}

Palavras-chave: Higiene; Doenças transmitidas por alimentos; Contaminação.

\section{ABSTRACT}

This study aimed to evaluate the hygienic and conservatory conditions of homemade mayonnaise sold in the city of Juazeiro do Norte-CE. Through microbiological analysis, the acquired samples were inoculated in the Brain Heart Infusion (BHI) enrichment medium, where they remained for 24 hours in the greenhouse, then the inoculated samples were seeded in the culture media Agar Mannitol Salgado, Agar SS (Salmonella-Shiguella ) and EMB Agar Methylene Blue Eosin (EMB), after 24 hours, bacterial identifications were made using the Gram stain method and biochemical tests for species identification. 36 samples were collected, $80.6 \%$ of which had bacterial contamination, among the bacteria found $89.6 \%$ were Stapylococcus aureus, $6.9 \%$ were Escherichia coli and 3.5\% were Salmonella $\mathrm{sp}$. The results obtained through this research may be related to storage and contamination due to inadequate hygiene.

Keyword: Hygiene; Foodborne diseases; Contamination. 


\section{INTRODUÇÃO}

A maionese caseira é conhecida também como maionese de baixa acidez por possuir um $\mathrm{pH}$ igual ou maior que 4,2, esse tipo de maionese é apreciado justamente por possuir essa característica, uma vez que as demais produzidas industrialmente possuem um alto teor de acidificação (ŠEVELOVÁ; GOLIAN, 2019). Segundo Gomes et al. (2014) a adição de óleos vegetais como ingrediente na preparação dessas maioneses pode minimizar a atividade dos enteropatógenos comumente encontrados no ovo.

A maionese caseira vem ganhando espaço no mercado a cada dia, é o molho mais consumido nas últimas décadas. Dessa forma, esse alimento deve sempre estar sob refrigeração, pois além de ter a sobrevida preservada, os riscos de contaminações por patógenos oportunistas são minimizados (SILVA et al., 2019). A contaminação pode ocorrer tanto durante o preparo do alimento derivado de ingredientes contaminados ou após o preparo caso não seja conservado adequadamente (GUERRA; MIGUEL, 2011).

$\mathrm{O}$ consumo da maionese caseira tem sido questionado por ser considerado um alimento que oferece riscos ao consumidor por ter como matéria prima o ovo de galinha cru, no qual comumente encontra-se a bactéria do gênero Salmonella sp. (GOMES, et al., 2014). O ovo é um dos portadores da bactéria Salmonella enteritidis principal causador da salmonelose uma doença transmitida por alimentos (DTA) muito comum nos últimos anos, uma vez que esse tipo de micro-organismo encontra-se presente fisiologicamente no intestino de aves, sendo assim transmitidos para os ovos, que são utilizados na preparação de diversos alimentos como pães, bolos e maioneses (ELIAS, 2014; DA SILVA ROBAZZA, et al., 2016).

Dentre as doenças mais frequentes nos últimos anos aquelas transmitidas por alimentos encontram-se em destaque, as mesmas podem ser acarretadas por diversos fatores como, higiene, refrigeração, manipulação incorreta, ou até mesmo utilização de ingredientes estragados (SOUSA JÚNIOR, et al., 2015; NESTLÉ, 2019). Dentre os micro-organismos causadores de infecção encontram-se em destaque bactérias da microbiota natural humana como Escherichia coli e Sthaphylococcus aureus (MALHEIROS; PAULA; TONDO, 2007).

A verificação da presença de coliformes como por exemplo Escherichia coli é de suma importância para avaliar as condições higiênicas e sanitárias da produção e conservação do alimento, pois a presença do mesmo é indicativo de contaminação fecal (CARDOSO et al., 2001). Algumas bactérias são comumente encontradas na flora bacteriana normal, como por exemplo Sthaphylococcus aureus, é encontrada fisiologicamente na pele e orofaringe, por ter esse tipo de característica o principal veículo de contaminação de alimentos por Staphylococcus sp. é o próprio manipulador portador do agente etiológico (KLEIN; GOULART, 2008).

Mediante o elevado consumo de maionese caseira e sua vasta comercialização principalmente pelo mercado ambulante do município de Juazeiro do Norte (CORDEIRO; VANDESMET, 2014), o trabalho teve como objetivo avaliar as condições higiênicas e conservatórias desse alimento.

\section{MATÉRIAIS E MÉTODOS}

\section{Local de realização do estudo e amostragem}

Foram adquiridas 36 amostras de maioneses caseiras aleatoriamente em locais onde se era oferecido de livre acesso aos consumidores, como lanchonetes, restaurantes e em comércios ambulantes da cidade de Juazeiro do Norte-Ceará. Foi realizado, pelo próprio autor, um check-list e relação às condições dos locais dos estabelecimentos onde eram recebidos os clientes, afim de verificar a relação de alguns fatores potencialmente causadores de contaminação e proliferação bacteriana. $\mathrm{O}$ estudo foi de caráter analítico descritivo para relatar a presença de Staphylococcus aureus, Salmonella sp. e Escherichia coli.

\section{Coleta das amostras e processamento}

Sacos plásticos que continha as amostras e eram entregues aos clientes foram coletados e colocados em caixas de isopor com gelo e levadas para o laboratório de microbiologia, onde todas as embalagens passaram por processo desinfecção com álcool a $70 \%$ antes da realização das análises. Logo após, as amostras foram abertas uma a uma com um bisturi estéril, em seguida retirou-se uma alçada de cada amostra e inoculou-se em meio de enriquecimento BHI (Brain Heart Infusion) encubando o meio por 24 horas em estufa microbiológica à $37^{\circ} \mathrm{C}$.

\section{Identificação de Staphylococcus aureus, Salmonella sp. e Escherichia coli}

Para identificação de Staphylococcus aureus, a partir do BHI com crescimento bacteriológico fez-se o semeio por técnica de esgotamento no meio Ágar Manitol, em seguida incubou-se a placa em uma estufa a $37^{\circ} \mathrm{C}$ pelo período de 24 horas. Staphylococcus aureus, por ser uma bactéria fermentadora de manitol, produz colônias grandes e rodeadas mudando o meio para cor amarela (SIMÕES et al., 2013).

Após a observação do crescimento em ágar 
manitol foram realizados as provas catalase e coagulase para confirmação da espécie. Para realização da prova de catalase foi colocada uma gota de peróxido de hidrogênio $(\mathrm{H} 2 \mathrm{O} 2)$ a $3 \%$ (v/v) em uma lâmina estéril e em seguida com o auxílio de uma alça de platina estéril, pegou-se uma colônia do meio de cultura, a mesma foi colocada sobre a gota para observação da formação de bolhas (BRASIL, 2013).

As colônias com positividade nos testes de catalase foram submetidas ao teste de coagulase, a fim de confirmar a espécie de Staphylococcus (ARANTES et al., 2013). Para realização do teste da coagulase em tubo retirou-se com o auxílio de uma alça de platina estéril uma colônia, colocou a mesma juntamente a $0,5 \mathrm{~mL}$ de plasma citratado utilizado no controle de qualidade da Clínica Escola da UNILEÃO. Este foi incubado por no mínimo 4 horas à $37^{\circ} \mathrm{C}$ em estufa para posterior observação do coágulo (BRASIL, 2013).

Para identificação de Salmonella sp. e Escherichia coli, a partir do BHI com crescimento bacteriano foi feito o semeio de todas as amostras, através da técnica de esgotamento, nos meios SS e EMB, os quais foram incubados em estufa a $37^{\circ} \mathrm{C}$ por 24 horas. Após a observação das placas de petri com crescimento bacteriano, os microrganismos foram identificados por meio da coloração de Gram e submetidos aos testes bioquímicos de Âgar TSI, Ágar Citrato de Simmons, meio SIM, Ágar Fenilalanina e Ágar Ureia de Christensen (BRASIL, 2016).

\section{RESULTADOS E DISCUSSÃO}

Após o crescimetno microbiano e a realização dos testes, observou-se que dentre as amostras coletadas $80,6 \%$ delas apresentaram contaminação por algum dos tipos de microrganismos pesquisados. A porcentagem do crescimento microbiano nas amostras de maioneses caseiras comercializadas em Juazeiro do Norte-CE, foram expressas no Gráfico 1.

Gráfico 1. Resultados obtidos por meio de análises microbiológicas para Escherichia coli, Salmonella sp. $e$ Staphylococcus aureus em maioneses caseiras comercializadas no município de Juazeiro do Norte-CE.

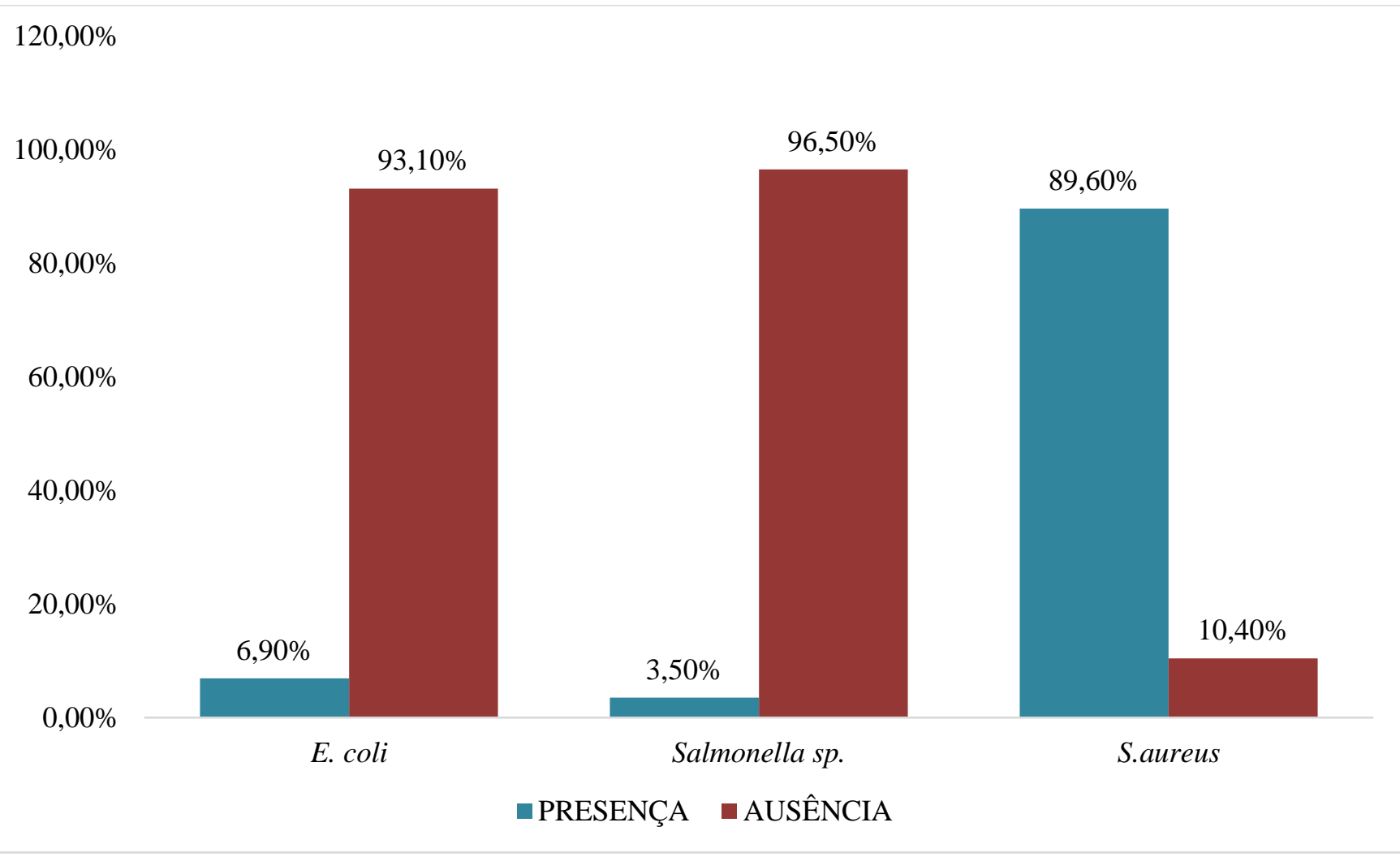




\section{Staphylococcus aureus}

O microrganismo que apresentou maior incidência durante a pesquisa foi Staphylococcus aureus com um percentual equivalente a aproximadamente $73 \%$ das amostras obtidas. Cordeiro; Vandesmet (2014) realizaram análises microbiológicas em maioneses caseiras produzidas e consumidas em lanchonetes na cidade de Juazeiro do Norte (CE) e os resultados revelaram que $100 \%$ das amostras obtidas apresentavam contaminação, dentre elas 50\% eram causadas por Staphylococcus aureus, o que confere uma desconformidade com a legislação a qual informa que deve haver ausência de bactérias como E. coli, Salmonella sp. e um resultado $\leq 103$ Unidades Formadoras de Colônias por mililitro (UFC/mL) (BRASIL, 2001).

No estudo de Maas et al. (2020), os quais analisaram maioneses caseiras de lanchonestes comercializados em Ji - Paraná, Rondônia, não foi evidenciado a presença de bactérias do gênero Staphylococcus, mas encontraram bactérias como Salmonella spp. e Colformes termotolerantes, estas que são potencialmente patogênicas. Microrganismos do gênero Staphylococcus são consideradas uma bactéria patogênica causadora de vários tipos de infecções tais como pneumonia, quadros de sepse e intoxicações intestinais, esta última sendo de extrema importância por ser uma das causas de ingestão de alimentos contaminados por esse micro-organismo (SANTOS et al., 2007; MACEDO et al., 2016).

\section{Escherichia coli}

Para Escherichia coli os resultados foram de 5,55\% em 36 amostras coletadas. Consiste em uma bactéria Gram-negativa, anaeróbia facultativa e que possui a capacidade de fermentar carboidratos como a glicose, a infecção pode ocorrer através da ingestão de cepas enterotoxigênicas presentes em alimentos ou água contaminada, os sintomas são causados devido a destruição de células do intestino grosso por uma toxina produzida pela bactéria (ALVES, 2012).

Em um estudo realizado por Fisher (2013) no estado do Rio Grande do Sul, constatou- se a presença de Escherichia coli em 52,8\% das amostras de maioneses obtidas, no entanto em outro estudo realizado por Sousa (2006) a bactéria foi encontrada em apenas $12,4 \%$ das amostras coletadas no município de São Carlos-SP.

\section{Salmonella sp.}

A bactéria Salmonella enteritidis está presente fisiologicamente no intestino das aves, e pode contaminar o ovo, alimento comumente consumido e utilizado na produção de pães, bolos e molhos como a maionese caseira, a mesma pode causar infecções severas com uma sintomatologia composta por febre, dores abdominais, dores de cabeça, vômito e melena (fezes com presença de sangue) entre outros (PISANI et al., 2010).

Em 36 amostras coletadas apenas 2,8\% apresentaram a presença de Salmonella sp. porém em um estudo realizado por Silva et al. (2011) em Pombal-PB, observou-se a presença da mesma em $75 \%$ das amostras obtidas em lanchonetes, já em outro estudo realizado por Cardoso; Tessari (2013) revelou que a bactéria não foi encontrada em nenhuma das amostras.

A Tabela 1 é composta por resultados do check-list referente aos locais onde as amostras foram obtidas. De acordo com o mesmo em relação as formas de armazenamento apenas 5,5\% das amostras eram armazenadas e refrigeradas corretamente, em relação as embalagens $11,1 \%$ delas estavam em perfeitas condições, as demais apresentavam marcas de sujeira e má higienização, quanto a higiene do local 5,5\% deles encontravamse em perfeito estado, quanto a data de fabricação das maioneses apenas $16,6 \%$ dos comerciantes se prontificaram a informar. 
Tabela 1. Check-list aplicado aos vendedores no momento da coleta.

\begin{tabular}{ccc}
\hline PERGUNTAS & SIM & NÃO \\
\hline As amostras são & $5,5 \%$ & $95,5 \%$ \\
armazenadas em freezers & & \\
ou geladeiras? & $11,1 \%$ & $88,9 \%$ \\
Os sacos plásticos onde as & & \\
maioneses estavam & & \\
armazenadas & & $95,5 \%$ \\
encontravam-se em boas & & \\
condições? & $5,5 \%$ & $83,4 \%$ \\
limpo e higienizado? & & \\
O fabricante informou a \\
data de fabricação?
\end{tabular}

As DTAs, representam um grave problema de saúde pública, estudos realizados por Oliveira et al. (2010) relatam que existem cerca se 250 tipos de doenças que são veiculadas através de contaminação de alimentos. Os consumo de alimentos está relacionada principalmente com suas características físicas e sensoriais, como por exemplo cor, odor e aspecto, as contaminações podem ser de origem física, geralmente devido à manipulação e falta de higiene, ou de origem química, como a presença de toxinas produzidas por bactérias ou outros micro-organismos segundo Marchi et al. (2011).

Os métodos de conservação são utilizadas para aumentar a sobrevidas dos alimentos, baseando-se na redução de temperatura, redução do $\mathrm{pH}$, atividade da água ou desidratação dos alimentos, um dos principais métodos de conservação utilizados é a refrigeração, por ser um métdo simples e barato (VASCONCELOS, 2016). Segundo a portaria da RDC $\mathrm{N}^{\circ} 78$ publicada em 2009, alimentos como maioneses caseiras devem ser mantidos em constante refrigeração à uma temperatura inferior à $5^{\circ} \mathrm{C}$, impedindo que haja proliferação bacteriana.

\section{CONCLUSÃO}

Através dos resultados obtidos, foi observado que as contaminações, provavelmente, são provenientes do armazenamento e higienização inadequada, pois $80,5 \%$ das amostras coletadas apresentaram crescimento bacteriano fora dos padrões da legislação. Com base nos dados obtidos é necessário ocorra com frequência a fiscalização desses estabelecimentos por órgãos de vigilância sanitária, além de receberem informações sobre manipulação correta de alimentos e os risco que os mesmos ofertam a comunidade, principalmente devido à presença de bactérias como Escerichia coli e Samonella sp., essas que deveriam ser ausente neste tipo de alimento e que são microorganismos causadores de quadros diarreicos graves, já para Staphylococcus aureus, o maior problema associado são as toxinas que esta libera nos alimentos, problema muito comum nos casos de DTAs. 


\section{REFERÊNCIAS}

ALVES, A. R. F. Doenças alimentares de origem bacteriana. Dissertação (Mestrado em Ciências Farmacêuticas). Faculdade de Ciências da Saúde, Universidade Fernando Pessoa, Porto. 87f. 2012

ARANTES, T. et al. Avaliação da colonização e perfil de resistência de Staphylococcus aureus em amostras de secreção nasal de profissionais de enfermagem. Revista Brasileira de Farmácia, v. 94, n.1, 2013.

BRASIL. Agência Nacional de Vigilância Sanitária. Manual de Microbiologia Clinica para o Controle de Infecção Relacionada á Assistência à Saúde. Detecção e Identificação de bactérias de importância médica. Brasília, DF, 2013.

BRASIL. Agência Nacional de Vigilância Sanitária. Manual de Identificação de Microrganismos de Importância Clínica. Brasília, DF, 2016.

BRASIL; BRASIL. Resolução RDC n ${ }^{\circ} 12$, de 02 de janeiro de 2001. Aprova o Regulamento Técnico sobre padrões microbiológicos para alimentos. Diário Oficial [da] República Federativa do Brasil, v. 139, n. 7-E, 2001.

BRASIL. Resolução RDC N 78 de 30 de Janeiro de 2009. Diário Oficial da União. Porto Alegre, RS, 2009.

CARDOSO, A. L. S. P, et al. Pesquisa de coliformes totais e coliformes fecais analisados em ovos comerciais no laboratório de patologia avícola de Descaldado. Instituto Biológico, São Paulo, v.68, n.1, 2001.

CARDOSO, A. L. S. P.; TESSARI, E. N. C. Salmonella enteritidis em aves e na saúde pública: revisão de literatura. Revista Científica Eletrônica de Medicina Veterinária, Garça-SP, v.1, n.1, 2013.

CORDEIRO, P. M. D.; VANDESMET, V. C. S.. Análise microbiológica de maioneses caseiras temperadas produzidas e consumidas em lanchonetes da cidade do Juazeiro do Norte - Ceará. VI Semana de Iniciação Científica, Juazeiro do
Norte-CE, v. 1, n. 1, p., 2014.

DA SILVA ROBAZZA, W.; DACOREGGIO, M. V.; GALVÃO, A. C.; SCHITTLER, L. Modelagem do crescimento de Salmonella Enteritidis em maionese adicionada de óleo essencial de orégano. VETOR-Revista de Ciências Exatas e Engenharias, v. 26, n. 2, p. 51-60, 2016.

ELIAS, S. O. Modelagem dos parâmetros cinéticos de multiplicação de Salmonella enteridis SE86 em maionese caseira e práticas de preparo, estocagem e consumo desse alimento no Rio Grande do Sul. Dissertação - Programa de Pós-Graduação em Microbiologia Agrícola e do Ambiente, Universidade Federal do Rio Grande do Sul. 2014.

FISCHER, M. M. Contaminação Microbiológica de alimentos em surtos de doenças transmitidas por alimentos no estados do Rio Grande do Sul entre 2004 e 2012. Trabalho de Conclusão de Curso em Engenharia de Alimentos, Universidade Federal do Rio Grande do Sul. 2013.

GOMES, I. A. et al. Sobrevivência de Salmonella enteritidis em Maionese Caseira. Blucher Food Science Proceedings. Rio de Janeiro, v.1, n.1, 2014. DOI: $10.5151 /$ foodsci-microal-267.

GOMES, I. A. Avaliação Microbiológica de Maionese Contendo Antimicrobiano Natural", p. 41-42 . In: Proceedings of the XII Latin American Congress on Food Microbiology and Hygiene [=Blucher Food Science Proceedings, v.1, n.1]. São Paulo: Blucher, 2014. DOI 10.5151/foodscimicroal-287.

GUERRA, C. B, MIGUEL, D. P. Staphylococcus coagulase positiva e coliformes fecais em pratos frios adicionados de molho de maionese. FAZU em Revista, Uberaba, n. 8, p. 131-136, 2011.

MAAS, A. et al. Avaliação microbiológica de maionese caseira comercializada no município de Ji-Paraná, Rondônia. Ciência \& DesenvolvimentoRevista Eletrônica da FAINOR, v. 13, n. 1, 2020. DOI: $10.11602 / 1984-4271.2020 .13 .1 .12$ 
MACEDO, V. F.; ZANARDO, J. G.; LOPES, R. P. C.; MENDONÇA, H. F. M. S.; EAYMUNDO, N. L. S.; MORAES, R. Prevalência de coliformes e Staphylococcus aureus em mãos de manipuladores de alimentos de feira livre de Vitória-ES. Salus Journal Health Science, v. 2, n. 2, p. 27-38, 2016. DOI: https://dx.doi.org/ 10.5935/24477826.20160014 .

MALHEIROS, P. S.; PAULA, C. M. D.; TONDO, E. C. Cinética de crescimento de Salmonella enteritidis envolvida em surtos alimentares no RS: uma comparação com linhagens de outros sorovares. Food Science and Technology, v. 27, n. 4, p. $751-755$, 2007. DOI: 10.1590/S010120612007000400013.

MARCHI, D. M. et al. Ocorrência de surtos de doenças transmitidas por alimentos no Município de Chapecó, Estado de Santa Catarina, Brasil, no período de 1995 a 2007. Epidemiologia e serviços de saúde, v. 20, n. 3, p. 401-407, 2011. DOI: 10.5123/S1679-49742011000300015.

NESTLÉ, SA Aspectos gerais da segurança microbiológica de alimentos: fontes de. Manual Internacional de Segurança Alimentar: Ciência, Regulamento Internacional e Controle , p. 397, 2019.

OLIVEIRA, A. B. A.; DE PAULA, C. M. D.; CAPALONGA, R.; DE ITAPEMA CARDOSO, M. R.; TONDO, E. C. Doenças Transmitidas por Alimentos: Principais Agentes Etiológicos, Alimentos Envolvidos e Fatores Predisponentes. Clinical \& Biomedical Research, v. 30, n. 3, 2010.

SIMÔES, M.; ROCHA, M. M. M.; PISANI, B.; PRANDI, M. Â. G.; LEMES-MARQUES, E. G. Salmonella enteritidis: importância do inquérito epidemiológico, análise de alimentos e coprocultura na elucidação de 167 surtos alimentares. Revista Instituto Adolfo Lutz, São Paulo, v. 69, n. 4, 2010.

KLEIN, G.; GOULART, L. S. Prevalência de Staphylococcus aureus multirresistentes em amostras biológicas do Laboratório Osvaldo Cruz, Uruguaiana-RS. Revista Brasileira de Farmácia, v. 82, p. 121-4, 2008.
SANTOS, A. L. et al. Staphylococcus aureus: visitando uma cepa de importância hospitalar. Jornal Brasileiro de Patologia e Medicina Laboratorial, v. 43, n. 6, p. 413-423, 2007. DOI: 10.1590/S1676-24442007000600005.

ŠEVELOVÁ, M.; GOLIAN, J. Application of Natural Substances to Reduce pH Value of EggBased Mayonnaise Products. Ywność: naukatechnologia-jakość , n. 2 (119), p. 110-123, 2019. DOI: $10.15193 / z n t j / 2019 / 119 / 289$.

SILVA, E. V.; NETO, J. F. S.; MELO, F. S. N.; ARAÚJO, A. S. Análise da qualidade microbiológica de maioneses comercializadas em Pombal. Cad. Verde Agroecol. Desenvol. Sustentavel, v. 1, n. 1, 2011.

SILVA, L. D. M. D.; DIAS, N. D. S.; OLIVEIRA, N. S.; COSTA, T. F.; CARVALHO, I. A. Avaliação da qualidade microbiológica de maionese caseira comercializada em food trucks em São Luís-MA. Higiene Alimentar. p. 2311-2313, 2019.

SIMÕES, T. V. M. D et al. Identificação laboratorial de Staphylococcus aureus em leite bovino Aracaju: Embrapa Tabuleiros Costeiros, 2013.

SOUSA, C. P. Segurança alimentar e doenças veiculadas por alimentos: utilização do grupo coliforme como um dos indicadores de qualidade de alimentos. Revista APS, v. 9, n. 1, p. 83-88, 2006.

SOUSA JÚNOR, D. L.; VANDESMET, V. C. S.; MENDES, C. F. C.; LEANDRO, L. M. G. Análise bacteriológica de queijos tipo coalho comercializados no município de Crato, Ceará. Revista Interfaces: Saúde, Humanas e Tecnologia, v. 3, n. 8, 2015. DOI: 10.16891/2317-434X.265.

VASCONCELOS, M. A. S.; MELO, F. A. B. Conservação de alimentos. 2016. 